\section{Melatonin expression in periodontal disease}

Gómez-Moreno G, Cutando-Soriano A, Arana C, Galindo P, Bolaños J, AcuñaCastroviejo D, Wang H-L. Melatonin expression in periodontal disease. J Periodont Res 2007; 42: 536-540. (C) 2007 The Authors. Journal compilation @ 2007 Blackwell Munksgaard

Background and Objective: It was the purpose of this study to examine the relationship between periodontal diseases and melatonin level.

Material and Methods: Forty-six patients with periodontal disease, together with 26 age- and gender-matched healthy controls, were included. Periodontal status was assessed using the Community Periodontal Index. Plasma and salivary melatonin levels were determined using specific commercial radioimmunoassays, whereas lymphocyte subpopulations (e.g. CD3, CD4, CD8, C19 and natural killer cells) were analyzed using flow cytometry.

Results: Patients with periodontal disease had significantly $(p<0.001)$ lower plasma $(9.46 \pm 3.18 \mathrm{pg} / \mathrm{mL})$ and saliva $(2.55 \pm 0.99 \mathrm{pg} / \mathrm{mL})$ melatonin levels than healthy control patients $(14.33 \pm 4.05$ and $4.22 \pm 0.87 \mathrm{pg} / \mathrm{mL}$, respectively). A biphasic relationhip was observed between plasma melatonin levels and Community Periodontal Indices. The plasma melatonin level was reduced in patients with a lower Community Periodontal Index value (1 or 2) and increased in patients with a higher Community Periodontal Index value (3 or 4). Salivary melatonin parallels the changes of plasma melatonin. The higher the Community Periodontal Index, the older the patient and the higher the total lymphocyte counts. CD4 concentrations also increased as the disease worsened.

Conclusion: The results obtained from this study suggest that melatonin could act as a protective function in fighting periodontal infection. However, further studies in this area are encouraged.
G. Gómez-Moreno ${ }^{1}$, A. CutandoSoriano', C. Arana ${ }^{2}$, P. Galindo ${ }^{3}$, J. Bolaños ${ }^{4}$, D. AcuñaCastroviejo $^{2}$, H.-L. Wang ${ }^{5}$

${ }^{1}$ Department of Special Care in Dentistry, School of Dentistry, ${ }^{2}$ Department of Physiology, Institute of Biotechnology, ${ }^{3}$ Oral Surgery Department, School of Dentistry, ${ }^{4}$ Statistics and Operational Research Department, School of Biblioteconomy and Documentation, University of Granada, Granada, Spain and ${ }^{5}$ Department of Periodontics and Oral Medicine, School of Dentistry, University of Michigan, Ann Arbor, MI, USA

Professor Antonio Cutando-Soriano, Department of Special Care in Dentistry, School of Dentistry, University of Granada, Colegio Máximo s/n, Campus de Cartuja, E-18071 Granada, Spain Tel: +34 958570301

Fax: +34958249653

e-mail: acutando@ugr.es

Key words: lymphocyte populations; melatonin; periodontal disease

Accepted for publication November 24, 2006
Melatonin, or $N$-acetyl-5-methoxytryptamine, is a hormone synthesized and secreted mainly in the pineal gland. It is released during the night via postsynaptic activation of the $\beta$-adrenergic receptors, thereby earning it the name of nocturnal messenger $(1,2)$. The pineal gland cells (or pinealocytes) respond to changes in the light/darkness cycle, causing their metabolic activity to synchronize with the 24-h day period (a phenomenon known as a circadian rhythm), mediated by the hypothalamic suprachiasmic nucleus. Peak melatonin secretion occurs in healthy subjects between 24:00 $\mathrm{h}$ and
$02: 00 \mathrm{~h}$, and the lowest secretion is observed between 12:00 $\mathrm{h}$ and 14:00 h. The production of melatonin declines after the age of 40-45 years, with a continuing reduction in its levels with increasing age $(3,4)$.

Currently, melatonin is not regarded as a hormone in the classical sense, but rather as a cell protector, because it is not synthesized in a single organ and does not exert effects upon a specific target organ (5). By far, most of the melatonin released into the bloodstream $(95 \%)$ is metabolized and conjugated in the liver, whereas in the central nervous system it is rapidly oxidized to $N$-acetyl-5-methoxykynuramine - a substance representing 15\% of the total urinary metabolites of the hormone (6).

Melatonin diffuses passively into saliva via the bloodstream, and salivary melatonin can be reliably assayed. The ratio between plasma and salivary melatonin in a (24-h) cycle varies from 0.24 to 0.33 , which means that the salivary melatonin concentration is equivalent to $\approx 24-33 \%$ of the plasma levels (7-9). Approximately $70 \%$ of plasma melatonin is bound to plasma albumin, with no appreciable amounts of such protein-bound melatonin being 
found in the saliva. Thus, salivary melatonin represents the portion of circulating melatonin not bound to proteins (i.e. the free fraction of the hormone). Melatonin modulates immune responses, protects cells via anti-inflammatory effects (acting as an antioxidant and free radical scavenger), stimulates type I collagen synthesis and promotes bone formation (10-27).

An important consideration in periodontal disease is the generation of free radicals (28), some of which derive from the oral bacteria themselves, others originating from the induced immune response (29-30). It has been suggested that an increase in both reactive oxygen and nitrogen species during periodontal disease is responsible for the oxidative damage to periodontal tissues (31). The increase in free radical production co-exists with a decrease in antioxidant defense. The imbalance between the pro-oxidant and antioxidant systems may lead to further oxidative attack and to substantial deterioration of the periodontal tissues $(32,33)$.

However, the relationship between periodontal diseases and melatonin level remains unknown. Hence, the present study was conducted to examine the relationship between periodontal disease and melatonin levels, as well as to assess the lymphocyte subpopulations (e.g. CD3, CD4, CD8, CD19 and natural killer) and their relationship to melatonin.

\section{Material and methods}

A total of 72 subjects were included in the study. Informed consent was obtained from all patients before participation in the study, which was approved by the University Ethics Committee and performed in accordance with the Code of Ethics of the World Medical Association according to the Declaration of Helsinki. The subjects were divided into two groups: control (26 healthy subjects, 15 women and 11 men, $47.2 \pm 9.1$ years); and test (46 age- and gender-matched patients with periodontal disease).

A dental and medical history was compiled for all patients, following World Health Organization criteria (34). The inclusion criteria for patients with periodontal disease were: age 18 65 years; and evidence of periodontal disease (e.g. bone loss, pocket depth). Exclusion criteria included the presence of other concomitant systemic disorders (such as epilepsy and schizophrenia) and diseases capable of affecting the immune system, such as chronic infectious and neoplastic processes $(35,36)$. Patients receiving pharmacological treatment that could alter melatonin levels were excluded from the study $(37,38)$.

Data were assessed by a singlemasked examiner. The intra-examiner reliability was calculated to be $84 \%$. Periodontal status was evaluated using the Community Periodontal Index (34). The Community Periodontal Index, currently recommended by the World Health Organization, consists of dividing the oral cavity into six sextants, with tooth indexing in each. Teeth index are $17 / 16$ for the first sextant, 11 for the second, $26 / 27$ for the third, $36 / 37$ for the fourth, 31 for the fifth and 47/46 for the sixth. Teeth were examined using a probe with two marks located at 3.5 and $5.5 \mathrm{~mm}$. The Community Periodontal Index scores used for recording periodontal status were as follows: $0=$ healthy periodontium; 1 = moderate bleeding; $2=$ presence of supra- or subgingival dental calculus; $3=$ periodontal pocket measuring $4-5 \mathrm{~mm}$; and $4=$ periodontal pocket $6 \mathrm{~mm}$ or more in depth.

\section{Determination of plasma melatonin}

Both test and control patients reported to the laboratory at $08: 00 \mathrm{~h}$ and were seated for $30 \mathrm{~min}$ before sampling. Blood samples $(20 \mathrm{~mL})$ were collected from the antecubital vein and centrifuged at $3000 \mathrm{~g}$ for $10 \mathrm{~min}$, followed by separation of the plasma fraction, which was then frozen $\left(-20^{\circ} \mathrm{C}\right)$ until assay (39). Plasma melatonin was determined using a commercial radioimmunoassay (DVD Biochemie GmbH, Marburg, Germany) (40,41), and a quality control was performed yielding intra- and interassay coefficients of variation of $10.5 \%$ and $5.9 \%$, respectively. The recovery of added melatonin was $86.3 \%$, with an assay sensitivity of $4.45 \mathrm{pg} / \mathrm{mL}$.

\section{Determination of salivary melatonin}

Saliva was obtained after chewing a piece of paraffin. Saliva produced during the first 2 min was discarded. Saliva $(5-10 \mathrm{~mL})$ was then collected during the following $5 \mathrm{~min}$, avoiding any possible contamination. The saliva samples were centrifuged at $3000 \mathrm{~g}$ for $20 \mathrm{~min}$, and the clear supernatant was frozen at $-20^{\circ} \mathrm{C}$. Melatonin levels in saliva were measured by radioimmunoassay (IBL GmbH, Hamburg, Germany) (42), and a quality control was performed yielding intra- and interassay coefficients of variation of $11.8 \%$ and $6.3 \%$, respectively. The recovery of added melatonin was $82.5 \%$, with an assay sensitivity of $2.09 \mathrm{pg} / \mathrm{mL}$.

\section{Determination of lymphocyte subpopulations}

A flow cytometer (Becton Dickinson FACS Vantage; Becton Dickinson, Franklin Lakes, NJ, USA) was used to quantify the lymphocyte subpopulations.

\section{Determination of $\mathrm{CD}^{+}$and $\mathrm{CD8}^{+}$ lymphocytes}

CD4 and CD8 are markers for $\mathrm{T}$ lymphocytes. Ortho Trio CD4/CD8/ CD3 monoclonal antibodies were used to identify these subpopulations. These antibodies are supplied as a mixture of three mouse monoclonal antibodies: CD4 conjugated to fluorescein isothiocyanate; CD8 conjugated to phycoerythrin; and CD3 conjugated to the tandem cyano-5phycoerythrin.

\section{Determination of $\mathrm{CD}^{+} 6^{+}$and $\mathrm{CD} 19^{+}$ lymphocytes}

CD16 and CD19 are markers for B lymphocytes. We used Ortho Trio CD16/CD19/CD3 monoclonal antibodies, which are supplied as a mixture of three mouse monoclonal antibodies (CD16 conjugated to fluorescein isothiocyanate, CD19 conjugated to phycoerythrin and CD3 conjugated to the tandem cyano-5-phycoerythrin), to identify these subpopulations. 


\section{Determination of natural killer cells}

The clone HP 2/1 (conjugated to fluorescein isothiocyanate) was used to identify natural killer cells. The reagent from Immunotech-Coulter Co. (Marseille, France) (cat. no: 1404) was used in the test.

\section{Statistical analysis}

Quantitative variables were expressed as mean \pm standard deviation, whereas absolute and relative frequencies were calculated for qualitative variables. The Mann-Whitney $U$-test was used to correlate quantitative with qualitative variables, and the Student's $t$-test was applied to compare the means of quantitative variables. The Spearman correlation coefficient was used to correlate quantitative and qualitative variables. The behavior of the lymphocyte subpopulations (expressed as percentages) was investigated using the Welch test. The relationship between a qualitative variable with more than two modalities (Community Periodontal Index) and the quantitative variables was examined by the Kruskal-Wallis test and/or one-way analysis of variance.

\section{Results}

Table 1 shows the comparison between periodontal disease patients and healthy individuals. The patients with periodontal disease had significantly lower plasma and salivary melatonin concentrations than the healthy subjects $(p<0.001)$. However, the salivary/ plasma melatonin ratio was similar in both groups. A significant, negative correlation was found between plasma melatonin and age in the control group $(r=-0.672, p<0.001)$. In healthy individuals, the older the patient, the higher the plasma melatonin concentration. However, this correlation was not noted in the periodontal disease patients ( $r=0.02$, not significant). When the percentage of lymphocyte subpopulations was examined, no difference was noted between test and control subjects, except for CD3. Periodontal disease patients showed a significantly higher percentage of $\mathrm{CD}^{+}{ }^{+}$lymphocytes than the control group $(p<0.05)$.

Application of the Kruskal-Wallis test yielded a $p$-value of $<0.001$, reflecting the age-dependent increase in the Community Periodontal Index (Table 2).

A biphasic relationship was observed between plasma melatonin and the Community Periodontal Index. The plasma melatonin level was decreased in patients with a Community Periodontal Index of 1-2 (the youngest patients), and increased to peak values in patients with a Community Periodontal Index of 4. Salivary melatonin was shown to parallel the changes of plasma melatonin (Fig. 1).

Patients with a Community Periodontal Index score of 4 showed the

Table 1. Comparison of the study variables between the controls and patients with periodontal disease

\begin{tabular}{lcc}
\hline Variable & & $\begin{array}{l}\text { Periodontitis } \\
\text { patients }(n=46)\end{array}$ \\
\hline Age & Controls $(n=26)$ & $52.07 \pm 9.3$ \\
$\mathrm{PM}$ & $47.2 \pm 9.1$ & $9.46 \pm 3.18^{* *}$ \\
$\mathrm{SM}$ & $14.33 \pm 4.05$ & $2.55 \pm 0.99 * *$ \\
$\mathrm{SM} / \mathrm{PM}$ ratio & $4.22 \pm 0.87$ & $0.31 \pm 0.07$ \\
$\mathrm{CD}^{+}$ & $0.30 \pm 0.06$ & $78.39 \pm 7.89^{*} * *$ \\
$\mathrm{CD}^{+} 9^{+}$ & $73 \pm 11.2$ & $10.31 \pm 4.43$ \\
$\mathrm{CD}^{+}$ & $9.5 \pm 3.0$ & $46.56 \pm 9.17$ \\
$\mathrm{CD}^{+}$ & $44.5 \pm 13.7$ & $28.29 \pm 9.57$ \\
$\mathrm{NK}^{+}$ & $29.5 \pm 7.8$ & $11.91 \pm 6.35$ \\
\hline
\end{tabular}

Data are given as mean \pm SD. Age is expressed in years, melatonin in $\mathrm{pg} / \mathrm{mL}$, and the lymphocyte subpopulations in percentages. Values in parenthesis indicate the number of cases.

NK, natural killer; PM, plasma melatonin; SM, salivary melatonin.

$* * p<0.001$ vs. control.

$* * * p<0.05$ on applying the Welch test.

Table 2. Mean patient age according to the Community Periodontal Index (CPI) score

\begin{tabular}{lrl}
\hline CPI & $n$ & Age (years) \\
\hline 1 & 9 & $39.9 \pm 10.6$ \\
2 & 11 & $50.2 \pm 8.6$ \\
3 & 17 & $56.6 \pm 10.3$ \\
4 & 9 & $61.6 \pm 7.8$ \\
\hline
\end{tabular}

Data are expressed as the mean $\pm \mathrm{SD} ; n=$ number of cases.

highest T-cell counts (Fig. 2). On evaluating $\mathrm{CD}^{+}{ }^{+}$cell behaviour and the Community Periodontal Index $(\mathrm{F}=0.77$; not significant $)$, it was found that when the Community Periodontal Index was $\geq 3$, the $\mathrm{CD}^{+}$ lymphocyte count increased. Moreover, in patients with a Community Periodontal Index of 4 , the $\mathrm{CD} 8^{+}$

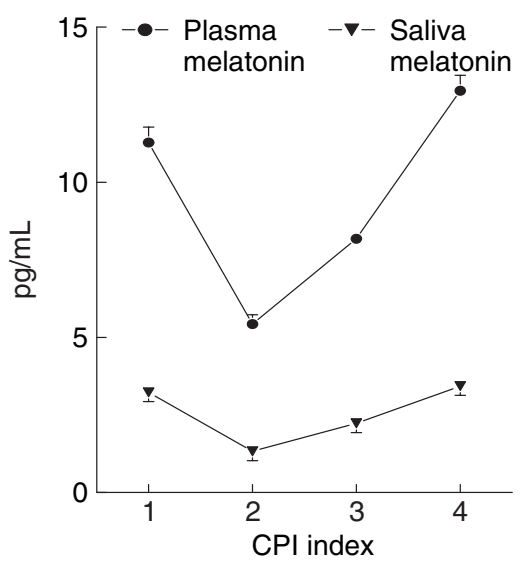

Fig. 1. Plasma and saliva melatonin levels in patients with periodontal disease.

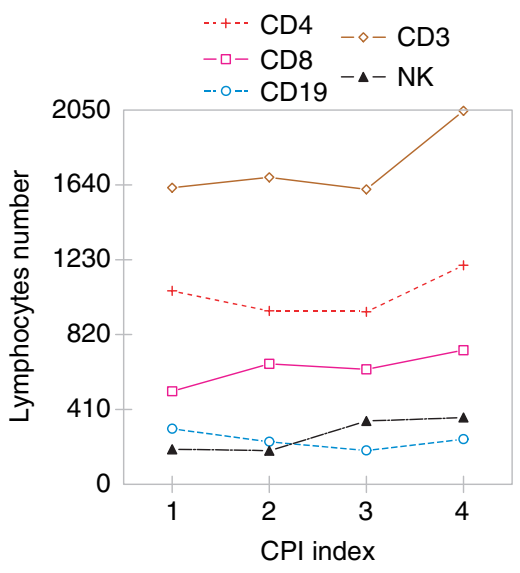

Fig. 2. Lymphocyte subpopulations among periodontal patients in relation to the Community Periodontal Index (CPI). NK, natural killer. 
T-cell count was increased $(\mathrm{F}=0.50$; not significant). The lowest $\mathrm{CD} 8^{+}$ count was observed in subjects with a Community Periodontal Index score of 1 ( $F=0.43$; not significant) (Fig. 2).

The patients with a Community Periodontal Index score of 1 presented the highest number of $\mathrm{B}$ lymphocytes (Fig. 2). The number of B lymphocytes decreased at a Community Periodontal Index score of 2 (age inflexion point) to a minimum at a Community Periodontal Index score of 3. Nevertheless, a rise was subsequently recorded at a Community Periodontal Index score of $4(F=0.77$; not significant). Regarding the natural killer cells ( $F=1.46$; not significant $)$, the counts increased with increasing Community Periodontal Index score.

An $r$ of $-0.305(p<0.05)$ was found between the percentage of CD $4^{+} \mathrm{T}$ cells and plasma melatonin concentration. Similar results were obtained on relating $\mathrm{CD} 4{ }^{+}$percentage to salivary melatonin, because the salivary concentrations of the hormone parallel those found in plasma $(r=-0.255 ; p<0.01)$.

\section{Discussion}

The importance of melatonin in relation to the immune system has been established, and melatonin is presently being used as coadjutant therapy in patients with certain tumors because it effectively reinforces the host immune defenses $(26,43,44)$. In the present study, melatonin levels in healthy subjects were significantly lower in older individuals. This situation could be attributed to the known decrease in the production of melatonin as individuals begin to age (i.e. at around 40-45 years old). However, the older patients preserved their response capacity to Community Periodontal Index scores of 3 and 4, attaining melatonin concentrations, in plasma (Community Periodontal Index 3, $8.5 \mathrm{pg} / \mathrm{mL}$; Community Periodontal Index 4, $13.5 \mathrm{pg} / \mathrm{mL}$ ) and in saliva (Community Periodontal Index 3, $2.5 \mathrm{pg} / \mathrm{mL}$; Community Periodontal Index $4,3.8 \mathrm{pg} / \mathrm{mL}$ ), that were lower than in healthy individuals but sufficient to maintain periodontal stability (Tables 1 and 2). In earlier studies $(22,23)$, this increase in salivary and plasma melatonin resulted in stimula- tion of the $\mathrm{CD} 4{ }^{+} \mathrm{T}$ cells, which possess membrane and nuclear receptors for the hormone $(20,21)$. This would stimulate the other immune cell populations via cytokine secretion (e.g. $\mathrm{CD}^{+}, \mathrm{CD}^{+} 9^{+}$, $\mathrm{CD}^{+}$and $\mathrm{CD}^{+}$cells with natural killer cell stimulation) - thereby facilitating the host reaction to an existing oral infection. This is in agreement with our data that indicated the higher the Community Periodontal Index index score, the greater the total lymphocyte counts $(\mathrm{F}=0.73$; not significant). Furthermore, our data also showed that when oral health is deficient and infectious foci develop (e.g. at a Community Periodontal Index score of 3 ), the CD ${ }^{+}$ lymphocyte count expanded - in close similarity to the melatonin concentration curve.

Data from our study showed that periodontal disease patients with lower $\mathrm{CD}^{+}$counts tend to exhibit higher melatonin levels. Considering that the immune cell populations increase as melatonin concentrations rise in situations of increasing Community Periodontal Index scores, the question arises as to what causes melatonin to increase at a given moment and stimulate the host immune system. In this context, melatonin possesses two functions of great interest to dental professionals: (i) its capacity to scavenge free radicals, thereby exerting antioxidative action (clearly surpassing all known antioxidants such as vitamin $\mathrm{C}, \mathrm{E}$ and coenzyme Q) (45-49); and (ii) the cellprotective effect exerted by melatonin in situations of inflammation $(13,28)$, stimulating bone regeneration by favoring collagen type I production (18) and modulating osteoblast and osteoclast activity $(16,19)$.

On examining the effects of melatonin upon the immune system, it may be considered that abundant reactive oxygen species are produced in situations of periodontal disease, characterized by an increase in peroxidation products generated by the infiltrating polymorphonuclear cell population (31), this, in turn, leading to an increase in melatonin levels. From our perspective, this not only would stimulate the immune system through the plasma fraction of the hormone, but would also afford local protection though the salivary melatonin fraction (50). As a result, the bone and cell population affected by the periodontal process would be protected from the reactive oxygen species generated by the existing inflammatory process, and bone repair would also be stimulated. Such effects could open new perspectives for the treatment of oral inflammatory processes $(50,51)$. In conclusion, the results obtained from this study suggest that melatonin could have a protective function in fighting periodontal infection. However, future studies in this area are encouraged to validate the initial results reported here.

\section{Acknowledgements}

This work was carried out partially with the assistance of grants CTS-263 from the Consejería de Educación, Junta de Andalucía, Spain.

\section{References}

1. Bergstrom WH, Hakanson DO. Melatonin: the dark force. Adv Pediatr 1998; 45:91-106.

2. Deguchi T, Axelrod J. Control of circadian change of serotonin $\mathrm{N}$-acetyltransferase in the pineal gland by $\beta$-adrenergic receptor. Proc Natl Acad Sci USA 1973;70:2411-2414.

3. Brainard GC, Petterborg LJ, Richardson BA, Reiter RJ. Pineal melatonin in syrian hamsters: circadian and seasonal rhythms in animals maintained under laboratory and natural conditions. Neuroendocrinology 1982;35:342-348.

4. Reiter RJ. Pineal melatonin: cell biology of its synthesis and physiological interactions. Endocr Rev 1991;12:151-180.

5. Vakkuri O, Leppaluoto J, Kauppila A. Oral administration and distribution of melatonin in human serum, saliva and urine. Life Sci 1985;37:489-495.

6. Wurtman RJ, Moskowitz M. The pineal organ (first of two parts). $N$ Engl J Med 1977;296:1329-1333.

7. Laakso ML, Porkka-Heiskanen T, Alila A, Stenberg D, Johansson G. Correlation between salivary and serum melatonin: dependence on serum melatonin levels. J Pineal Res 1990;9:39-50.

8. McIntyre IM, Norman TR, Burrows GD, Armstrong SM. Melatonin rhythm in human plasma and saliva. $J$ Pineal Res 1987;4:177-183.

9. Vakkuri O. Diurnal rhythm of melatonin in human saliva. Acta Physiol Scand 1985;124:409-412. 
10. Acuña-Castroviejo D, Escames G, Carazo A, León J, Khaldy H, Reiter RJ. Melatonin, mitochondrial homeostasis and mitochondrial-related diseases. Curr Top Med Chem 2002;2:133-151.

11. Allegra M, Reiter RJ, Tan DX, Gentile C, Tesoriere L, Livrea MA. The chemistry of melatonin's interaction with reactive species. J Pineal Res 2003;34:1-10.

12. Reiter RJ, Guerrero JM, García JJ, Acuña-Castroviejo $D$. Reactive oxygen intermediates, molecular damage, and aging. Ann N Y Acad Sci 1998;854:410-424.

13. Chapple IL. Reactive oxygen species and antioxidants in inflammatory diseases. J Clin Periodontol 1997;24:287-296.

14. Martín M, Macías M, Escames G, León J, Acuña-Castroviejo D. Melatonin, but not vitamins $\mathrm{C}$ and $\mathrm{E}$, maintains glutathione homeostasis in t-butyl hydroperoxideinduced mitochondrial oxidative stress FASEB J 2000;14:1677-1679.

15. Tan DX, Manchester LC, Reiter RJ, Qi WB, Karbownik M, Calvo JR. Significance of melatonin in antioxidative defense system: reactions and products. Biol Signals Recept 2000;9:137-159.

16. Cardinali DP, Ladizesky MG, Boggio V, Cutrera RA, Mautalen C. Melatonin effects on bone: experimental facts and clinical perspectives. J Pineal Res 2003; 34:81-87.

17. Ladizesky MG, Boggio V, Albornoz LE, Castrillon PO, Mautalen C, Cardinali DP. Melatonin increases oestradiol-induced bone formation in ovariectomized rats. $J$ Pineal Res 2003;34:143-151.

18. Nakade O, Koyama H, Arijii H, Yajima A, Kaku T. Melatonin stimulates proliferation and type I collagen synthesis in human bone cells in vitro. $J$ Pineal Res 1999;27:106-110.

19. Ostrowska Z, Kos-Kudla B, Marek B, Swietochowswka E, Gorki J. Assessment of the relationship between circadian variations of salivary melatonin levels and type I collagen metabolism in postmenopausal obese women. Neuroendocrinology 2001;22:121-127.

20. García-Maurino S, González-Haba MG, Calvo JR, Goberna R, Guerrero JM. Involvement of nuclear binding sites for melatonin in the regulation of IL-2 and IL-6 production by human blood mononuclear cells. J Neuroimmunol 1998;92:7684.

21. Guerrero JM, Pozo D, García-Maurino S, Osuna C, Molinero P, Calvo JR. Involvement of nuclear receptors in the enhanced IL-2 production by melatonin in Jurkat cells. Ann NY Acad Sci 2000;91:7397-7403.

22. Maestroni GJ, Conti A. The pineal neurohormone melatonin stimulates activated $\mathrm{CD} 4+$, Thy- $1+$ cells to release opioid agonist(s) with immunoenhancing and anti-stress properties. $J$ Neuroimmunol 1990;28:167-176.

23. Maestroni GJ. The immunotherapeutic potential of melatonin. Expert Opin Invest Drugs 2001;10:467-476.

24. Maestroni GJ, Conti A, Pierpaoli W. Role of the pineal gland in immunity. Melatonin antagonizes the immunosuppressive effect of acute stress via an opiatergic mechanism. Immunology 1988;63:465-469.

25. Caroleo MC, Frasca D, Nistico G, Doria G. Melatonin as immunomodulator in immunodeficient mice. Immunopharmacology 1992;23:81-89.

26. Lissoni P, Barni S, Archili C et al. Endocrine effects of a 24-hour intravenous infusion of interleukin-2 in the immunotherapy of cancer. Anticancer Res 1990;10:753-757.

27. Kelley KW. Growth hormone in immunobiology. In: Ader R, Felten N, Cohen $\mathrm{N}$, eds. Psychoneuroimmunology II. San Diego: Academic Press, 1991:377-403.

28. Battino M, Bullon P, Wilson M, Newman H. Oxidative injury and inflammatory periodontal diseases: the challenge of antioxidants to free radicals and reactive oxygen species. Crit Rev Oral Biol Med 1999;10:458-476.

29. Gustafson A, Asman B. Increased release of free oxygen radicals from peripheral neutrophils in adult periodontitis after Fc $\gamma$-receptor stimulation. $J$ Clin Periodontol 1996;23:38-44.

30. Zambon JJ, Reynolds H, Fisher JG, Shlossman M, Dunford R, Genco RJ. Microbiological and immunological studies of adult periodontitis in patients with non insulin-dependent diabetes mellitus. J Periodontol 1998;59:23-31.

31. Kimura S, Yonemura $\mathrm{T}$, Kaya $\mathrm{H}$ Increased oxidative product formation by peripheral blood polymorphonuclear leukocytes in human periodontal disease. J Periodont Res 1993;28:197-203.

32. Halliwell B. Free radicals, antioxidants and human disease: curiosity, cause or consequence. Lancet 1994;344:721-724.

33. Sies H. Oxidative stress: oxidants and antioxidants. Exp Physiol 1997;82:191295

34. WHO. Oral Health Surveys: Basic Meth$o d s, 4$ th edn. World Health Organization: Geneva, 1997.

35. Kawamura N, Kim Y, Asukai N. Suppression of cellular immunity in men with a past history of posttraumatic stress disorder. Am J Psychiatry 2001;158:484-486.

36. Kronfol Z, Remick DG. Cytokines and the brain: implications for clinical psychiatry. Am J Psychiatry 2000;157:683-694.

37. Glaser R, Rabin B, Chesney M, Cohen S, Natelson B. Stress-induced immunomodulation: implications for infectious diseases? J Am Med Assoc 1999;281:22682270 .
38. Gómez F, Ruiz P, Briceno F, López R, Michan A. Treatment with progesterone analogues decreases macrophage $\mathrm{Fc}$ gamma receptor expression. Clin Immunol Immunopathol 1998;89:231-239.

39. Kennaway DJ, Voultsios A. Circadian rhythm of free melatonin in human plasma. $J$ Clin Endocrinol Metab 1998; 83:1013-1015.

40. Arent J, Paunier L, Sizonenko PC. Melatonin radioimmunoassay. $J$ Clin Endocrinol Metab 1975;40:347-350.

41. Kennaway DJ, Frith RG, Phillipou G Matthews CD, Seamark RF. A specific radioimmunoassay for melatonin in biological tissue and fluids and its validation by gas chromatograph-mass spectrometry. Endocrinology 1977;101:119-127.

42. Miles A, Thomas DR, Grey JE, Pugh AJ. Salivary melatonin assay in laboratory medicine - longitudinal profiles of secretion in healthy men. Clin Chem 1987;33:1957-1959.

43. Neri B, De Leonardis V, Gemelli MT Melatonin as biological response modifier in cancer patients. Anticancer Res 1998; 18:1329-1332.

44. Solar P. Melatonin and its wide-spectrum effects: use of melatonin in the treatment of tumors. Cesk Fysiol 1999;48:27-40.

45. Baydas G, Canatan H, Turkoglu A. Comparative analysis of the protective effects of melatonin and vitamin $\mathrm{E}$ on streptozocin-induced diabetes mellitus. $J$ Pineal Res 2002;32:225-230.

46. Hanioka T, Mcree JT, Xia LJ. Therapy with coenzyme $\mathrm{Q}_{10}$ for patients with periodontal disease. 2. Effect of coenzyme $\mathrm{Q}_{10}$ for patients on the immune system. J Dent Health 1993;43:667-672.

47. Reiter RJ, Tan DX, Acuña-Castroviejo D. Melatonin: mechanisms and actions as an antioxidant. Curr Top Biophys 2000; 24:171-183

48. Tan DX, Reiter RJ, Manchester LC et al. Chemical and physical properties and potential mechanisms: melatonin as a broad spectrum antioxidant and free radical scavenger. Curr Top Med Chem 2002;2:181-197.

49. Zhang Z, Araghinikman M, Liang B et al. Prevention of immune dysfunction and vitamin $\mathrm{E}$ loss by dehydroepiandrosterone and melatonin supplementation during murine retrovirus infection. Immunology 1999;96:291-297.

50. Cutando A, Gómez-Moreno G, Villalba J, Ferrera MJ, Escames G, Acuña-Castroviejo D. Relationship between salivary melatonin levels and periodontal status in diabetic patients. J Pineal Res 2003; 35:239-244.

51. Moore S, Calder KA, Miller NJ, RiceEvans CA. Antioxidant activity of saliva and periodontal disease. Free Radic Res 1994;21:417-425. 